\title{
New Trajectories in Academia: Operating at the Intersection(s) of Rupture(s) Recovering Architectural, Cultural and Ecological Landscapes Through Design Acupunctures
}

\author{
SHANNON BASSETT \\ University at Buffalo, SUNY
}

How might we begin to recalibrate the processes and methodologies in which we teach and design in order to address pressing environmental paradigms and global stresses, both within a global perspective framed within broader academic discourse, while simultaneously addressing the local?

\section{RUPTURES THROUGH DESIGN ACUPUNCTURES}

This paper posits that these processes and methodologies might operate at the intersection of rupture(s) through design acupunctures. This includes working across scales of investigation, as well as multiple directions of flows, beyond that of architecture simply as object. Additionally, this includes the dispelling of binaries still prevailing in architectural discourse and practice. These projects operate at the intersection of ruptures, proposing alternative forms of design and development through the intersection of architecture, culture and ecological systems. This paper examines studios engaging in these simultaneous global, as well as local issues. The studio project, Speculative Surfaces for the Tianjin Eco-City, proposes an alternative form of development for the coastal/delta city of Tianjin Eco-City through landscape and ecology as urbanism. Shanghai Water Urbanisms recovers the Shanghai post-industrial waterfront through public design and ecology. Village Acupunctures examines a critical rethinking of the prototypical Chinese village, through an architecture research studio located in Anhui Village, China. Finally, Adopt a Farm engages architecture as strategic design, re-connecting Shanghai urban dwellers to the countryside through organic food, including choreographing the overlay of new digital networks and situated technologies.

Speculative Surfaces for the Tianjin Eco-City

The recent eco-city project, as well as the low-carbon city project, both in China, initially presented the potential to address a number of issues of sustainability. This project of the "model city" operates at once at the global scale, as well as the highest governmental scales in collaboration between the Central Chinese and Singapore governments. It can be critiqued that they have been lacking in an entirely integrative sustainable design, and that their construction and development have actually undermined their actual landscapes and the eco-system services in which they provide, in addition to being disruptive to ecologies and economies at the local scale.

This 14-week long urban design studio held during the Spring 2011 was framed through the lens of proposing an alternative form of development to the current proposal for the Tianjin Eco-city in the Bohai Sea Distirct of China, through a framework of landscape and ecology as urbanism. Much of the development currently occurring in China is putting a massive pressure of development onto the existing ecological and cultural landscapes. Cities are literally popping-up out of the proverbial landscape, as China shifts from being $80 \%$ rural to $80 \%$ urban, a figure being projected by some as happening by 2050 . This is particularly significant for a country which was predominantly agricultural, and where the majority of the population still lives in rural locations. Emerging new models such as those in the city of Chengdu are beginning to look at one based on urban-rural integration; in the "Modern Garden City " model derived from that of Ebenezer Howard's Garden City model from 1910. Other contemporary models have included "eco-cities" and "low-carbon cities."

Students travelled to China during their Spring break for three weeks during the Spring 2011. There they worked in collaboration with architecture and planning students from the Tianjin University School of Architecture and Planning there. This was an advance graduate studio in architecture addressing an urban design scale for the first time in the graduate architecture studio sequence. The premise of the studio was to question the current prevailing urbanization strategy for the model Chinese City. The notion of utopian cities and their representation through diagramming was also explored through examining a number of utopian visions of the city in the initial few weeks of the studio. A number of these seminal utopian proposals from the west have been translated and iterated into current prevailing models for new Chinese towns, including the Corbusier Modernist City, in addition to Hillberseimer's decentralized city. These include employing architectural prescriptive images of the Modernist Tower in a Park model. These architectural New Towns may be described as relentless, and they are a product of one aspect of the top-down government structure there, which governs them. This respects 


\section{RESIDENTIAL CONFIGURATION}
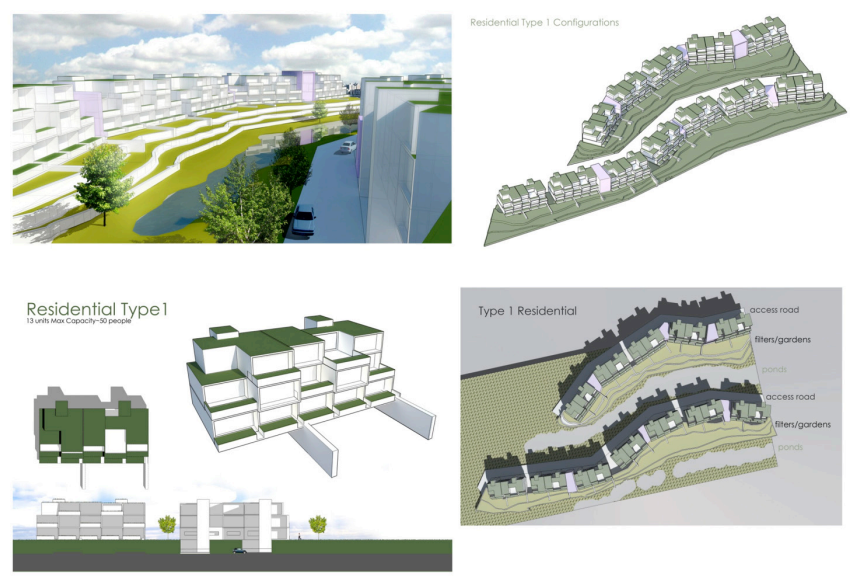

Figure 01: An Alternative Form of Developmet for the Tianjin Eco-City Speculative Surfaces for the Tianjin Eco-City-Architecture and Urban Design Studio-Proposal for Eco-City operates across scales of intervention, recovering cultural and ecological landscapes-Darci Chamberlain, Dimitar Dimitrov, Juan Esparza, Spring 2011, University of South Florida, Tampa, Florida, Graduate Architecture Studio

architectural control, including prescriptive zoning and the spacing between the towers, a function of maximizing light, air quality, as well as wind orientation. ${ }^{1}$

The student's proposals offered an alternative to the current eco-city proposal at different scales. At the neighborhood scale, the urban spaces of these developments, the so-called "spaces in between", do not possess the same qualities of the "interstitial, or "space in between" as do in the traditional spaces of Chinese cities. The traditional Chinese cities include the laneways of the traditional hutongs of China's northern cities between its courtyard housing. These are conducive to the activities and programs of China's civil society.

No more than twenty years ago, many of these interstitial spaces also served as productive space for agriculture and food production. Dr. Konjian Yu, landscape architect and Dean of the Peking University School of Architecture, has critiqued the appropriation of the aesthetic landscapes of the City Beautiful Movement, replacing the more productive landscape in a disconnect with China's agricultural history and landscapes. ${ }^{2}$

This was the first trip to China for all of the students. The studio's approach began from one of examining opportunities implicitly within the underlying infrastructure in this scheme across a spectrum of design scales. This project moves from the zoomed-out territorial investigation to the architectural scale. The open spaces of the development dual as spaces for the mitigation of storm water run-off and flooding, characterisitc to the larger Delta in which they are situated. These serve as productive agricultural landscapes which provide flexible spaces for recreational activities, in addition to creating alternative systems for movement such as bicycle systems. The students worked across scales of investigation. The constructed landscape manages part of the ecological and hydrological cycle. The designs at the architectural scale via the building massing are keyed into these larger landscape scales, with their design and massing for the collection of water, which stores it. The water is then treated in terraced bio-filters and retention ponds. Student designed architectural proposals which plug into the larger urban scales of the proposal. This simultaneity of design at differeing scales become part of the nested scales of the project framed through sustainability. These terraced bio-filters collect and clean the water, while at the same time as acting as the roof for a finer grain of micro-urbanism for the neighborhood unit. Schemes re-organized the open spaces in between the residential units. They also examined breaking the existing volumetric massing of the housing typologies. A finer grain of programs along these connectors creates micro-urbanism within the inner part of the block which links to the open green space systems. The constructed landscape achieves part of the open-space requirement and serves as an alternative to elevating the city up on a plinth.

The masterplan integrates a constructed wetland into the existing landscapes. A landscape buffer exists on the edges with the development setback from it as climate-ready estuaries, which permit flooding in the case of rising sea levels. The open-space systems are designed for the block scale and at the neighborhood, while creating an interconnected system.

The studio project was posed with a set of complexities which students needed to address in their response, operating across scales, manifested in an intrinsic understanding of the landscape, as well as its relationship to territory, and linked to the history and culture of the site and place.

In conclusion, this studio challenged architecture students in their designs to operate at the intersection of recovering architectural, cultural and ecological landscapes through design acupunctures. Designs depart from an attempt to understand the site's landscape and its morphology, while ultimately serving as its conceptual underpinnings and framework. The landscape was identified with the culture and locale of the site, from that of the territorial to the scales of the building responses. Students worked at the ruptures of multiple contexts such as informal vs. formal, rural vs. urban, constructed landscape vs. vernacular, as well as through the lens of the student's own cultural biases and views through their western perspectives. There also occured negotiations between the American and Chinese students with respect to biases and misperceptions in their considerations.

Village Acupunctures

The Studio, "Designing Village Acupunctures", examines a critical rethinking of the prototypical Chinese Village, through an architecture research studio in located in a village in Anhui province, China. This studio was run on two different occasions as two different models. This project included a studies abroad studio in China, as well as a graduate Architecture studio run in the Spring 2016 at the University at Buffalo School of Architecture and Planning. 


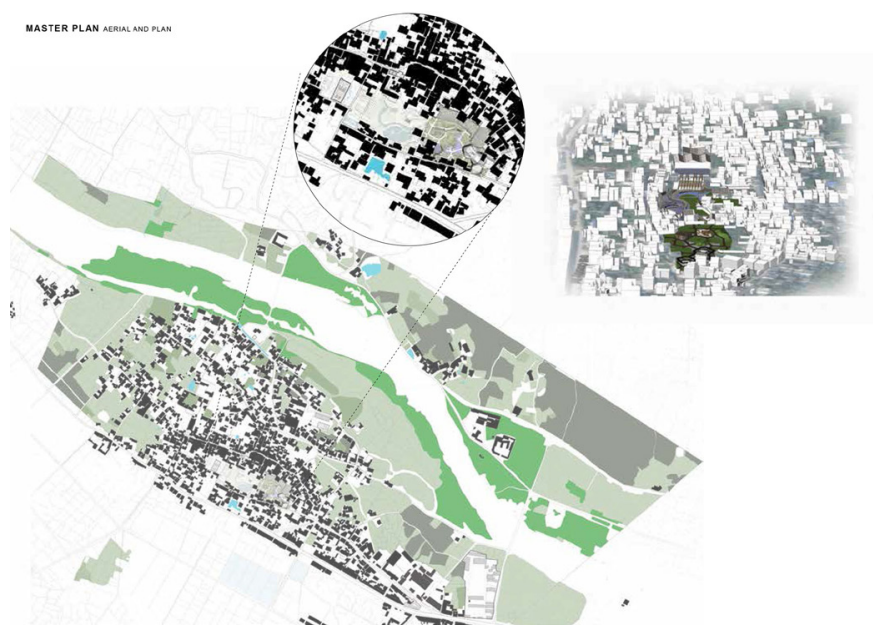

Figure 2: Mapping of the Ecological and Hydrological Systems of Xixinan, Anhui province, exploring the intrinsic relationship between the natural landscape and rural-urban morphology, as well as the nested scales of landscape and buliding. Students Eliana Drier, Nashon Jagroop, Marius Laurinkus, University at Buffalo School of Architecture and Planning, Graduate Architecture Studio, Summer Study Abroad Program, Summer 2015

This design studio asked students to consider proposing a series of architectural interventions with ecological planning in a rural village in China. Typological interventions at the architectural scale re-interpret village archetypes with hybrid programs, working simultaneously at the scales of the global and of the local.

This studio operated as two different models. The first was part of a nine-week study abroad program, working in part collaboration with the Peking University School of Architecture and Landscape Architecture and Turenscape, the Design Institute linked to Peking University. It was also run as a Graduate Options Studio at the Buffalo School of Architecture and Planning in the Spring 2016. The area is undergoing pressures for development. Its natural landscape of mountains (shan shui, the characters which signify mountain water) makes it a draw for tourism. As with the rest of China, an infrastructural network of high-speed rail infrastructure has collapsed spatial territories, now shortening the distance from Shanghai to Anhui. Additionally, the current high-speed rail infrastructure being built is currently suspended outside the gateway to the village.

The current village continues to operate as a functional agricultural village. At the same time, its history is one of culture and art and poetry. As part of a recent phenomena in China, in the wake of the ills of the industrializing and urbanizing city, the more affluent city dwellers who can afford to, are fleeing city life and many times have second homes in these villages. Again, the studio challenged architecture students to work across scales of investigation, as well as through multiple directions of flows, beyond that of architecture simply as object. Beginning with a series of mapping projects of the site working remotely in Beijing, the studio began to work with understanding the larger territory of the village by mapping its hydrological, as well as ecological systems. Located in the Huangshan mountains, both the village morphology as well as the architectural morphology has an intrinsic relationship to the natural landscapes, as well as its systems. As one student observed in reference to the irrigation systems running through the village... " Aside from their beauty, (the mountains) are also the source of water. It is almost poetic to see the source of such an important element of daily life. From the beauty of the mountains, to the river, to the canals, into the house...The realization that this sort of culture has existed for thousands of years...humbles you into a deeper appreciation of nature and all that it offers. The mountains bring life and sustenance to the Hui people. It evokes a feeling that is very difficult to explain." ${ }^{3}$
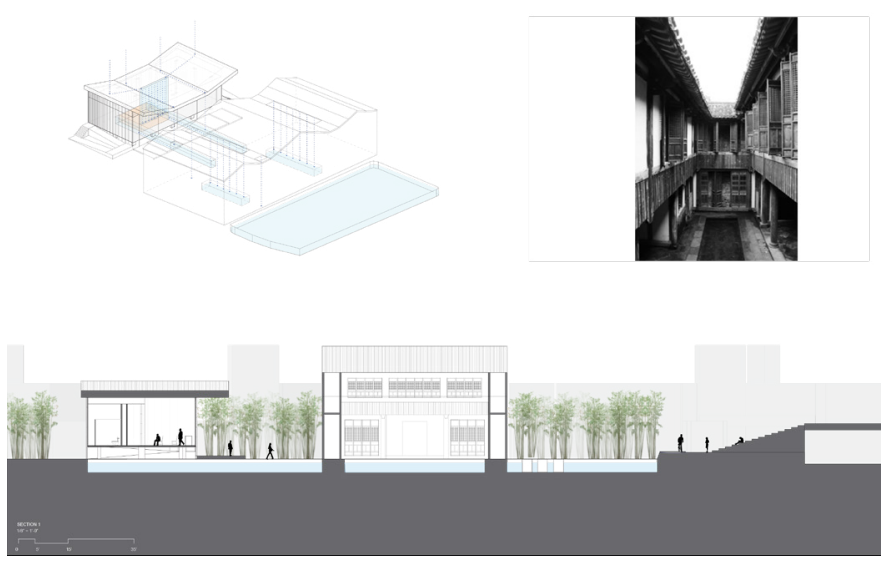

Figure 3: Architectural Proposal for Visitor's Center, Xixinan, Anhui province, China, Eliana Drier, University at Buffalo School of Architecture and Planning

The design integrates the ecological and hydrological systems of the Viillage into the design intervention.

From this scalar understanding of the natural landscapes, students worked in design teams of three. 

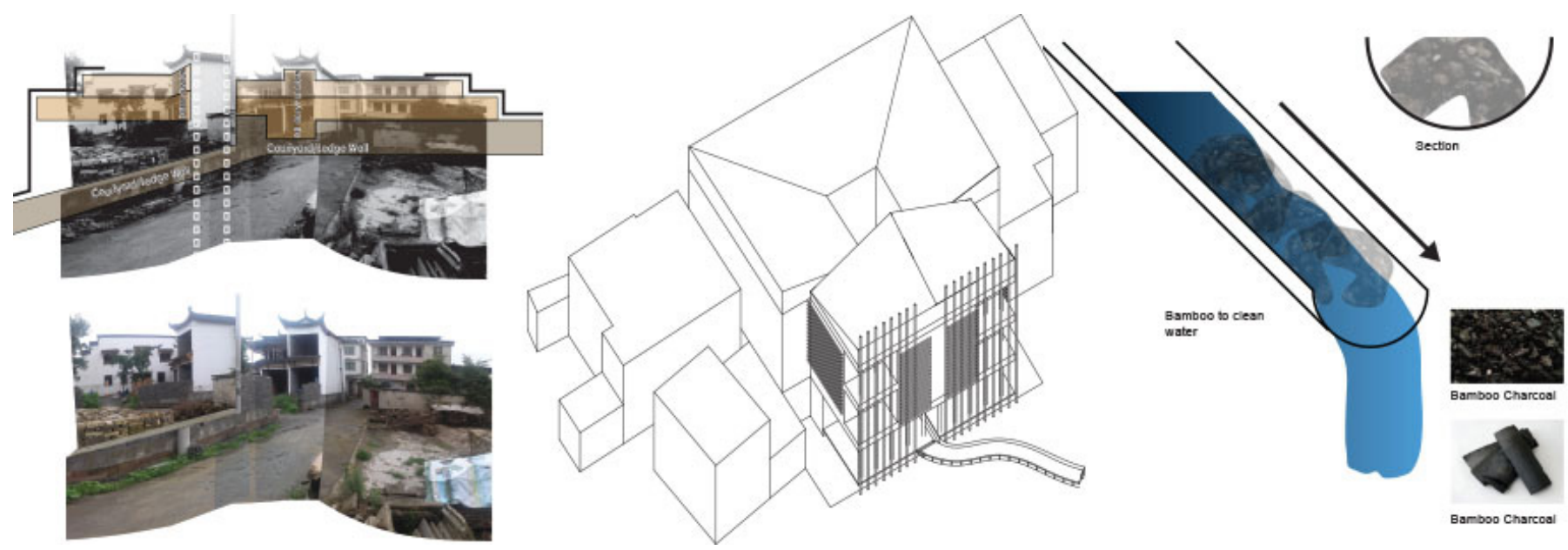

Figure 4: Architectural Proposal for Perimeter Block intervention, Bamboo scaffolding and water purification through charcoal-lined bamboo, Xixinan, Anhui province, Carl Stanboro, University at Buffalo School of Architecture and Planning

Shanghai Water Urbanisms was a month-long design charrette held in Shanghai, in part in collaboration with the Tongji University Smart Sustainable Living Lab Sino-Finnish Design Institute. Students presented their projects to the Shanghai Xuhui District Urban Planning Bureau there. The site was located on a brownfield on the Huangpu River in Shanghai across from the site, which hosted the 2010 World Expo. The project proposed redeveloping the waterfront in order to extend the existing iconic Bund, Shanghai's open space system, to the south, thus creating an interconnected system to the main city. Formerly industrial, the project examined and proposed methods of remediating the site, as well as introducing new hybrid programs onto it. Students were first introduced to pre-industrial water city morphologies along the Yangtze River Delta and their formerly more intrinsic relationships. Located on a delta-like condition, Shanghai is characterized by canals snaking through it, which had been filled due to industrialization. At one scale, the site was catalytic in that connected to a larger area meant to restitch the area back to the Shanghai rail station whose site is currently under redevelopment. With this larger understanding, students designed a public space, which recovered the landscape, while as the same time as making the connections to the larger city systems, as well as made connections to an area of redevelopment, the Shanghai South Railway station. Its post-industrial condition was endemic of a larger economic phenomena. 


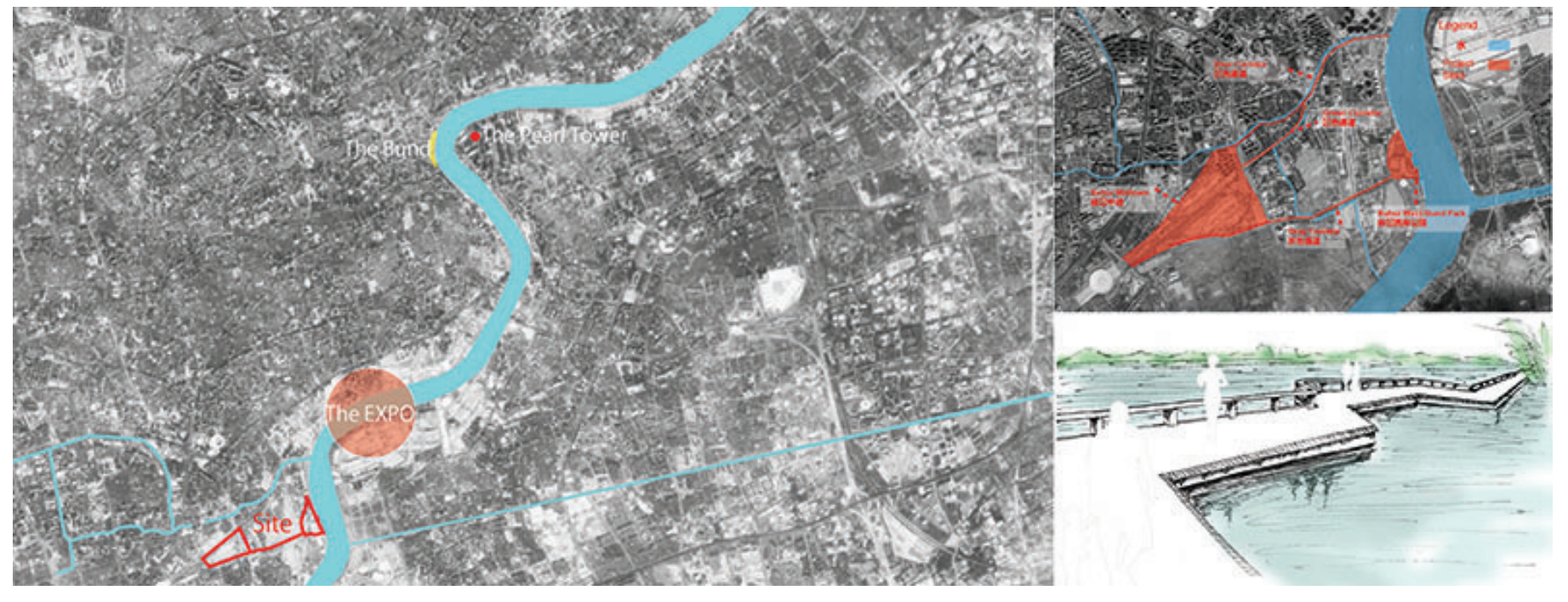

Figure 5: Shanghai Water Urbanisms, Design Workshop in China, Yuki Toda, Matthew Myers, Ashwini Karve, Andrew Dearing Site of design, brownfield site adjacent to Huangpu River, serves as a catalyst for reconnecting the city to its waterfront to the east, as well as the existing open-space system of the Bund, as well as the Shanghai train station.

\section{CONCLUSIONS}

In conclusion, these projects offer frameworks for new processes and methodologies for designing and teaching architecture, addressing predominant paradigms of pressing environmental issues and global stresses, while addressing both global perspectives within broader academic discourse, while at the same time as addressing the local. Key to the framework of these projects is pedagogical architectural exploration which at once can be simultaneously engaged in multiples scales of design and investigation. These so called "ruptures" operate at the intersection of rupture(s) through design acupunctures.

\section{ENDNOTES}

1. Studio, "Speculative Surfaces for the Tianjin Eco-City" was featured in Urban Flux, 2011, pp66-85

2. Dr. Kongjian Yu, Lecture "The Art of Survival, School of Architecture and Community Design, University of South Florida, Tampa, Florida, 2008.

3. Quoted from student Alan Chan, University at Buffalo, School of Architecture and Planning, studio participant in Summer Study Abroad Studio in China, "Village Acupunctures in Xixinan", Summer 2015. Also featured in B/a+p Alumni Magazine featuring the studio, by Lisa Gagnon, pp10-12 